\title{
Does Social Disagreement Attenuate Partisan Motivated Reasoning? A Test Case Concerning Economic Evaluations
}

\author{
Joshua Robison* \\ Department of Political Science, Aarhus University, Aarhus \\ ${ }^{\star}$ Corresponding author. Email: jrobison@ps.au.dk
}

(Received 6 July 2017; revised 4 January 2018; accepted 6 June 2018; First published online 26 October 2018)

\begin{abstract}
Research on partisan motivated reasoning shows that citizens perceive the world differently based upon their partisan allegiances. Here we marshal evidence from several national surveys to investigate whether partisan motivated reasoning is attenuated among partisans situated within disagreeable political discussion networks. While our analyses suggest that exposure to interpersonal disagreement is associated with weaker partisan identities, we find limited evidence that disagreement attenuates partisan differences in knowledge or retrospective evaluations of the economy. This suggests that interpersonal disagreement is unlikely to help reduce partisan motivated reasoning. Our results thus speak to important debates concerning the influence of social discussion on political attitudes, the nature of partisan motivated reasoning and the ability of citizens to hold elites accountable.
\end{abstract}

Keywords motivated reasoning; economic evaluations; political knowledge; political discussion

Representative democracies require citizens to be capable of holding elites to account via the rewarding of good performance and the punishing of bad. It is against the backdrop of this normative claim that recent work on partisan motivated reasoning becomes worrying. Partisans generally try to expose themselves predominantly to partisan friendly messages and vigorously dispute information harmful to their favored party (Druckman, Peterson, and Slothuus 2013; Iyengar and Hahn 2009; Stroud 2011). These processes of selective attention and interpretation may result in citizens being unable to accurately perceive elite performance thereby threatening accountability efforts (Druckman 2014; Jerit and Barabas 2012; Lebo and Cassino 2007; Ramirez and Erickson 2014). These studies raise an important question: what types of contexts constrain partisan motivated reasoning?

Recent reviews have suggested one potential context that may attenuate partisan motivated reasoning: disagreeable political discussion networks (Bolsen, Druckman, and Cook 2014, 253; Leeper and Slothuus 2014, 144). The motivation to affirm and defend one's partisan identity is not an unbounded impulse, but one that can be mitigated by the presence of continual streams of party-challenging information (Lavine, Johnston, and Steenbergen 2012; Redlawsk, Civettini, and Emmerson 2010). While partisans may work to construct news diets so as to minimize their mediated exposure to this type of information, political discussion with friends, family and coworkers may operate as an alternative, and fairly pervasive, source of partisan challenge. Individuals may encounter reasons to question their partisan allegiances via such discussions which, in turn, may prompt them to hold weaker partisan identities and thereby experience a diminished motivation to selectively process political information (Klofstad, Sokhey, and McClurg 
2013; Sinclair 2012). The possibility that social disagreement may attenuate partisan biases is politically and theoretically important, but one that has not received much prior attention. ${ }^{1}$ Our central question is thus: does exposure to political disagreement within one's political discussion network attenuate partisan motivated reasoning?

We contribute to the literatures on partisan motivated reasoning and interpersonal discussion by exploring their interrelationship with regards to a politically important manifestation of partisan motivated reasoning: citizens' propensity to evaluate the national economy based on the partisanship of the incumbent government (Bartels 2008; Duch, Palmer, and Anderson 2000; Enns and McAvoy 2012; Evans and Andersen 2006; Evans and Pickup 2010). Existing work shows that supporters of the incumbent party will discount negative, and opponents positive, information about economic performance. Partisan disagreements over economic performance raise troubling questions regarding the ability of the mass public to discharge its role in holding elites accountable given the important role such evaluations play as a consideration guiding vote choices (Duch and Stevenson 2008; Fiorina 1981). ${ }^{2}$ We will thus explore whether social disagreement disrupts these patterns. In particular, we will investigate whether the level of disagreement within a partisan's political discussion network is associated with an increased propensity to make partisanincongruent evaluations of the economy when called for, e.g. for out-partisans to render more positive evaluations of economic conditions during good economic times.

We marshal the best available observational evidence concerning the relationship between interpersonal disagreement and partisan motivated reasoning on economic matters. Specifically, we use evidence from five national surveys from the United States to explore how partisan differences in factual knowledge and subjective retrospective assessments of the economy vary according to the extent of disagreement in partisans' discussion networks. Our results provide meager support for the claim that interpersonal disagreement attenuates partisan bias in this domain. On the one hand, exposure to disagreement is associated with an increased propensity to correctly answer factual questions about the economy when such facts are incongruent with the respondent's partisan identity, but the evidence is somewhat mixed across the surveys. On the other hand, we find that network disagreement does little to consistently affect partisans' subjective evaluations of the economy in a way consistent with an attenuation of partisan reasoning strategies. Our results thus suggest that interpersonal disagreement is not a panacea for partisan motivated reasoning.

\section{Partisanship, Motivated Cognition and Economic Assessments}

The past several decades have witnessed a resurgence of work on the motivated bases of human cognition and has resulted in an understanding that human reasoning and information processing is goal-directed (Kunda 1990). In the political realm particular attention has been paid to directional goals (Leeper and Slothuus 2014; Lodge and Taber 2006; Nir 2011b). When directional goals are salient, which appears to be generally, individuals select and process information so as to favor a particular outcome, i.e. to affirm one's status in, and defend the validity of, one's partisan identity. Directional reasoning may manifest in selective exposure where individuals seek out attitudinally congruent information (Druckman, Fein, and Leeper 2012; Lodge and Taber 2006; Stroud 2011). Meanwhile, when discordant information is encountered directional goals stimulate active cognitive efforts to rationalize and reject this information (Lodge and Taber 2006; Lord, Ross, and Lepper 1979; Mullinix 2016). This work largely supports the

\footnotetext{
${ }^{1}$ One notable exception is Klar (2014), which we discuss in greater detail below.

${ }^{2}$ Of course, even if partisans agree that the economy is doing well or poorly they may still disagree about who or what is responsible, with partisanship guiding this attributional process, as in Bisgaard (2015) and Tilley and Hobolt (2011). However, this type of disagreement strikes us as less normatively problematic. Agreement on factual matters is a precursor to collective deliberation and thus intrinsically valuable.
} 
argument that partisans often see the world through a partisan perceptual screen (Bolsen, Druckman, and Cook 2014; Campbell et al. 1960).

The operation of partisan guided reasoning processes can help explain partisan disagreements concerning economic performance. First, partisans may pay attention to different news sources which report economic news in a divergent manner (Larcinese, Puglisi, and Snyder 2011; Stroud 2011). In addition, partisans may also selectively perceive information about economic performance when it is received (Bartels 2008; Enns, Kellstedt, and McAvoy 2012; Lebo and Cassino 2007; Ramirez and Erickson 2014). Finally, partisans may be motivated to selectively report their perceptions so as to maintain the positive value of their identity (Bullock et al. 2015; Prior, Sood, and Khanna 2015). ${ }^{3}$ While partisan disagreements over the economy are not entirely the fault of these partisan biases, economic perceptions appear to be strongly guided by their relevance for the validity of one's partisan identity. ${ }^{4}$ This recurrent finding raises a politically and normatively important question: what types of political and social contexts constrain partisan motivated reasoning?

\section{Social Networks, Disagreement and The Potential Reduction of Partisan Bias}

Individuals do not form political opinions in a vacuum. Rather, political attitudes are greatly influenced by interactions with other citizens and particularly the friends, family and acquaintances that comprise their political discussion networks (Huckfeldt and Sprague 1995; Mutz 2006; Sinclair 2012). Particularly relevant for our purposes are studies demonstrating that the extent of political disagreement within these networks is consequential. In particular, prior work connects exposure to interpersonal disagreement with weaker (e.g. less extreme and more ambivalent) issue and candidate preferences, greater openness to persuasion, enhanced knowledge of the legitimate rationales for opposing viewpoints, and with a greater openness to voting for candidates from different political parties (Bloom and Levitan 2011; Huckfeldt, Mendez, and Osborn 2004; Lupton, Singh, and Thornton 2015; Mutz 2002a; Mutz 2002b; Pattie and Johnston 2008; Robison, Leeper, and Druckman 2018; Sinclair 2012; Visser and Mirabile 2004). Individuals situated within discussion networks with high levels of disagreement appear to be more 'deliberative' in their political attitude formation processes. ${ }^{5}$

While the foregoing studies are not explicitly focused on partisan motivated reasoning, they nevertheless provide a reasonable basis for suggesting that interpersonal disagreement will also help attenuate partisan reasoning biases. ${ }^{6}$ However, we are aware of only one study that explicitly explores this possibility, Klar's (2014) experimental study showing that respondents assigned to a mixed discussion setting demonstrated less evidence of partisan bias in reactions to persuasive messages than those assigned to a discussion context consisting only of co-partisans. While important evidence, argumentative discussions in this study occurred in an evenly divided setting (i.e. four Democrats and four Republicans) among individuals who did not know each other, and

\footnotetext{
${ }^{3}$ Notably, Prior, Sood, and Khanna show this by invoking a social accountability motive on the part of respondents, i.e. a similar type of stimulus as explored here.

${ }^{4}$ There exist additional explanations for partisan disagreements in retrospective economic assessments. For instance, partisan groups may place differential weights on unemployment and inflation, thereby yielding different perceptions of the economy; see Gerber and Green (1999). However, studies of aggregate responses to economic information suggest that unemployment matters more than inflation for all partisan groups: see Enns, Kellstedt, and McAvoy (2012) and Enns and McAvoy (2012).

${ }^{5}$ While our focus lies on the discussions citizens have informally with their peers, research on small group decision making and democratic deliberation also highlight the importance of disagreement in opinion formation processes (e.g. Barabas 2004; Mendelberg 2002; Wojcieszak 2012). Perhaps particularly notable is the literature on group polarization wherein small group discussion on a decision tends to polarize initial opinions among those discussing the issue among the like-minded and de-polarize opinions among those discussing the issue in a more heterogeneous, or argumentative, setting (Isenberg 1986).
}

${ }^{6}$ As is done by Bolsen, Druckman, and Cook (2014), Druckman (2014), and Leeper and Slothuus (2014). 
thus had little expectation of future interactions, which may prevent easy generalization to more common networks wherein peers know each other, broadly expect to interact again in the future and where disagreement is more or less one-sided (Nir 2005, 2011a). Moreover, Klar could only look at the responses of Democratic students, leaving open the possibility that effects will vary across partisan groups or among older individuals. Ultimately, a test of the argument that exposure to interpersonal disagreement within discussion networks undermines directional motivated reasoning requires replication with evidence from more naturalistic discussion networks.

Why might an individual's susceptibility to partisan motivated reasoning vary alongside the level of political disagreement within their political discussion network? Information processing is not only guided by directional goals such as the desire to affirm one's partisan identity, but is instead a balancing act between directional, accuracy and efficiency goals (Chaiken, GinerSorolla, and Chen 1996; Lavine, Johnston, and Steenbergen 2012). The priority given to a directional goal will depend upon the relative strength of this goal. In the current context the directional goal is the motive to defend one's partisan identity, which is rooted in the strength and relevance of the partisan identity for the individual. As partisan identity strength increases, in other words, so too will an individual's propensity to act in such a way as to affirm the validity of their partisan allegiance (Huddy, Mason, and Aarøe 2015; Mullinix 2016).

Partisan motivated reasoning increases alongside identity strength. Crucially, higher levels of social disagreement are likely to be associated with weaker partisan identities much as they are with issue attitudes more generally (for instance: Klofstad, Sokhey, and McClurg 2013; Lavine, Johnston, and Steenbergen 2012; Sinclair 2012). The extent of disagreement within a network will influence the type of information an individual receives regarding political affairs. Agreeing partners, i.e. partners with the same partisan identity, provide identity-congruent information that can be used to further bolster the validity of one's partisan allegiance. Disagreeing partners, i.e. those with dissimilar partisan preferences, may instead provide identity-challenging information. For instance, discussions with disagreeing others provide insight into the legitimate rationales for the other side's positions which may lead to more positive views of the other side and hence identity ambivalence (Lavine, Johnston, and Steenbergen 2012; Mutz 2002a; Mutz and Mondak 2006; Pattie and Johnston 2008; Price, Cappella, and Nir 2002). In addition, partisans tend to believe the other side to be homogeneous in nature, which facilitates perceptions of party polarization and hence an increased likelihood that an individual will self-categorize as a partisan and work to defend their partisan identity (Ahler and Sood 2018; Druckman, Peterson, and Slothuus 2013). However, discussing politics with individuals from the other side can disrupt these stereotypes and mitigate perceptions of polarization, which should thus disrupt partisan self-categorization processes and hence reduce the relevance of the partisan identity to the individual (Buttice, Huckfeldt, and Ryan 2009; Lyons and Sokhey 2017). Finally, disagreeing others can be a conduit to information contained in media sources a partisan would otherwise ignore, thereby providing a route for party-critical information to reach them (Druckman, Levendusky, and McLain 2018). Given that interpersonal discussion networks tend to be tilted toward close ties, i.e. friends and family, this incongruent information is potentially more credible, and hence effective, than if it had been encountered from elite out-partisan sources (Huckfeldt 2001; Huckfeldt and Sprague 1995; Lupia 2002; Mutz 2006; Sinclair 2012). And, while exposure to disagreement may inspire efforts to counter-argue, continual exposure to incongruent information, as we might expect to occur in ongoing social relationships, can break down this tendency (Lodge and Taber 2006; Redlawsk, Civettini, and Emmerson 2010). Partisans within disagreeable networks may thus possess both the information necessary to come to more accurate understandings of the economy as well as a diminished motivation to resist this information due to weakened (i.e. less extreme or more ambivalent) identities.

If partisan motivated reasoning is rooted in the strength of an individual's partisan identity, and higher levels of disagreement undermine identity strength, then it is plausible that partisans 
within more argumentative networks will evince lesser evidence of partisan motivated reasoning. What would this look like? We focus on whether disagreement is associated with an increased likelihood that partisans express party-incongruent beliefs regarding the national economy as it is in this arena that motivated reasoning related biases should be most apparent. Our specific focus is on partisans' knowledge of facts regarding economic performance and their retrospective economic evaluations. If disagreement undermines partisan motivated reasoning, then it should help promote the expression of these incongruent beliefs when called for.

Hypothesis 1: Increasing levels of political disagreement will be associated with an increased likelihood of expressing partisan-incongruent beliefs about the national economy, all else equal.

To illustrate this hypothesis let us first consider individuals that identify with the same party as the incumbent government, what we will call in-partisans. These individuals will generally be motivated to process information to the advantage of their co-partisans in government. During positive economic conditions this is not too difficult as incoming economic information aligns with that motivation. However, when economic conditions sour there should exist friction between this party defensive motivation and incoming information that will depress the likelihood that in-partisans will correctly answer economy-related knowledge questions and report negative evaluations of the national economy. However, if the level of disagreement within a partisan's political discussion network attenuates partisan motivated reasoning, then we would expect to see an increased likelihood of correctly answering economy-related factual questions and reporting negative evaluations of the economy among this partisan group even though such beliefs clash with one's goal of defending one's partisan team. Our expectations regarding outpartisans are the inverse. We are interested in out-partisan reactions during positive economic conditions as this is when there should exist friction between partisan defensive motivations and one's incoming information. Our hypothesis holds that disagreement will be associated with increased knowledge and increasingly positive evaluations for this group in such contexts.

\section{Methods}

We draw on five national surveys conducted in the United States to investigate our hypotheses. Specifically, we use data from the US version of the 1992 Cross-National Election Project (CNEP), the 2000 ANES Time Series (TS), the panel component of the 2002 ANES Time Series wherein respondents from the 2000 ANES TS were reinterviewed (hereafter 2002 ANES Panel), the 2006 ANES Pilot and several waves from the 2008-9 ANES Panel survey. There are several advantages to using this array of data sources. First, the surveys were conducted in varying economic conditions, which enables us to test our specific in- and out-partisan expectations. ${ }^{7}$ Table A1 in the online appendix provides economic statistics for each survey. Broadly speaking, the surveys conducted in 1992, 2002 and 2008-9 were fielded during negative economic conditions, while those fielded in 2000 and 2006 took place in more positive economic conditions. A second advantage of using this array of surveys is that it enables us to look at contexts where a Democrat or a Republican was President and thus enables variation in which partisan team is considered 'in-partisans' and which are considered 'out-partisans'. Finally, the 2002 ANES Panel and 2008-9 ANES Panel surveys enable us to obtain some distance between the measurement of our independent variables (partisanship and network disagreement) and our dependent variables, as in both cases the former were measured anywhere from one month to two years prior in time to the latter.

\footnotetext{
${ }^{7}$ In addition, prior work suggests that individuals are more sensitive to negative than positive economic conditions and information and thus variation in economic conditions can enable us to avoid making inferences based on only a single economic context; see, for instance, Soroka (2006) and Stanig (2013).
} 


\section{Core independent variables: partisanship and network disagreement}

We will detail our dependent variables in the sections to come. However, let us first note the nature of our two main independent variables. Partisanship is a binary indicator coded so that partisans that identify with the same party as the incumbent President (in-partisans) are given a score of 1 and partisans identifying with the opposite party receive a score of 0 (out-partisans). Thus, we code Republican respondents as in-partisans in 1992, 2002 and 2006, when a President Bush occupied the White House while Democrats in these survey years are coded as out-partisans. Meanwhile, we code Republican respondents as out-partisans and Democrats as in-partisans in 2000 and the two 2009 panel waves due to the presence of a Democratic President at the time of the survey. Leaning partisans are included in this binary measure while pure Independents are excluded from the analysis, given the focus on difference in response between partisan groups.

Respondents to each survey completed a battery of items concerning their political discussion network. These batteries always began with a name-generator question wherein respondents were asked whether they discussed politics/important matters with anyone or not. Notably, asking individuals about peers with whom they discuss 'important matters' versus politics does not appear to elicit different types of responses (Klofstad, McClurg, and Rolfe 2009). On the ANES surveys, the network generators were included on the post-election wave of the 2000 ANES, the 2006 Pilot which occurred after the 2006 mid-term election, and the September 2008 wave of the 2008-9 ANES Panel which began in January 2008. Note that we are focusing here on those individuals that completed the battery, i.e. those that said they discuss politics or important matters with at least one person, as is customary (Mutz 2002b; Sinclair 2012; Sokhey and McClurg 2012).

Individuals that said yes to this initial question were then asked detailed questions concerning up to five (1992 CNEP), four (ANES 2000 TS/ANES 2002 Panel) or three (ANES 2006, ANES 2008-9) discussants. The types of individuals typically captured by these name generators tend to be relatively strong ties (i.e. close friends, spouses and family members), but co-workers, i.e. generally weaker ties, also represent a significant percentage of discussants as well (see Klofstad, McClurg, and Rolfe 2009, table 2). While these questions, and our resultant measures, focus on respondents' perceptions of their discussants, prior research suggests that individuals are often quite accurate in these perceptions and that it is the perception, not the reality, that influences individuals (Huckfeldt, Mendez, and Osborn 2004, 69; Huckfeldt and Sprague 1995, 154-5; Mutz 2002b).

On each survey respondents were asked about the political views of their named discussants. Respondents were asked about the Presidential candidate preference of each discussant in the 1992 CNEP and 2000 ANES TS/2002 ANES Panel surveys, while in the remainder of the surveys they were asked about discussant partisanship. Our measure of Network Disagreement was calculated by subtracting the number of discussants with the same PID or candidate preference, i.e. agreeing discussants (A), from the number of discussants with different preferences (D; Network Disagreement =D - A; Lupton, Singh, and Thornton 2015; Lupton and Thornton 2017). ${ }^{8}$ The resulting variable ranges from -5 to +5 on the $1992 \mathrm{CNEP},-4$ to +4 on the 2000 and 2002 ANES, and -3 to +3 on the 2006 and 2008-9 ANES surveys, with higher scores indicating greater potential exposure to disagreement. ${ }^{9}$ Respondents scoring below 0 are situated within networks with more agreeable than disagreeable partners, while those above 0 experience an

\footnotetext{
${ }^{8}$ Discussants for whom the respondent reported not knowing a political preference necessarily do not contribute to the disagreement measure as we do not have the information necessary to categorize these dyads. We discuss the nature of these 'missing' discussants in online Appendix C. Disagreeing dyads in this coding scheme count non-major party partners as disagreeing (i.e. a Democrat/Independent pairing). We investigate the consequences of this coding choice in online Appendix $\mathrm{C}$ and find that focusing only on major party dyads yields the same pattern of results reported below.

${ }^{9}$ In online Appendix D we explore alternative specifications of exposure to disagreement, including measures that incorporate information about the size of the network, frequency of political discussion, the perceived political sophistication of the discussants, the perceived closeness of discussants and how much the respondent 'generally' disagrees about political
} 
overall tilt toward disagreement in the network. While the mean value on this variable is below 0 for all surveys, most respondents nevertheless possess at least one disagreeable partner. ${ }^{10}$

\section{Control variables and dealing with potential selection issues}

Our data on social network composition are observational in nature, which necessarily limits our ability to speak to the causality of the relationships shown below. One potential worry is that individuals could plausibly select into networks based on the level of political disagreement. While we cannot remove such concerns we address them in two ways. First, Sinclair notes that social networks typically do not form based on shared political beliefs but instead on other social characteristics (Sinclair 2012). She thus recommends controlling 'for the social characteristics that generate homophily' as one means of reducing endogeneity concerns (Sinclair 2012, 16). All analyses reported here control for age, gender, education, race, family income, marital status and political interest/news attention for just this reason. ${ }^{11}$ In addition, the ANES analyses contain measures for the respondent's need for cognition and need to evaluate, which are included as controls because these cognitive style indicators have previously been connected with an individual's general propensity to engage in directional motivated reasoning. ${ }^{12}$ Second, we leverage the panel nature of the ANES surveys in analyses reported in online Appendix E by replicating our analyses using a measure of disagreement that has been preprocessed using a matching algorithm. Specifically, in each case we can use measures obtained in waves conducted prior to when network disagreement was measured to obtain greater balance between 'treated' (i.e. high levels of disagreement) and 'control' (i.e. low levels of disagreement) on a variety of predictors that may explain both a respondent's propensity to engage in partisan motivated reasoning and their selection into disagreeing networks (e.g. cognitive style, prior partisan identity strength and political sophistication). Notably, our substantive conclusions remain the same. While these tactics cannot fully deal with worries concerning self-selection and endogeneity, they are the best tools available to us here. We will return to this point in the conclusion.

\section{Results}

\section{Disagreement and knowledge of inconvenient facts}

Partisans within disagreeing discussion networks are expected to evince weaker motivations to defend their partisan identity, which should be associated with an increase in knowledge of partisan 'inconvenient' facts (Hypothesis 1). We can test this hypothesis using data from the 2000 ANES and 2008-9 ANES Panel surveys. In both cases respondents were asked to indicate whether they believed that the federal budget deficit had grown smaller, larger or stayed the same relative to some prior point in time. ${ }^{13}$ On the 2000 ANES this measure was asked in the

matters with the discussant into the D-A framework. Using these alternative specifications would not substantially change the conclusions we reach.

${ }^{10}$ The mean values were: -0.93 (SD: 2.01 ) in $1992,-1.05$ (1.63) in $2000,-1.16(1.64)$ in 2006 , and $-0.85(2.00)$ in 2008 . The median value for all four surveys was -1 . The percentage of respondents with at least one disagreeing discussant in their networks is 58\% (1992), 44\% (2000), 51\% (2006) and 59\% (2008).

${ }^{11}$ These variables are also important to account for insofar as they are likely to influence economic evaluations and knowledge (e.g. Conover, Feldman, and Knight 1986; Duch, Palmer, and Anderson 2000; Haller and Norporth 1997; Hetherington 1996). Also included in the models below are measures of network size and network sophistication.

${ }^{12}$ One potential concern here is that variables such as political interest/news attention, and perhaps even the cognitive style indicators, may themselves be endogenous to network composition, in which case controlling for them would introduce post-treatment bias to our estimates. We investigate the robustness of our estimates to this consideration in online Appendix B. We compare results from three models: no control variables, just (reasonably) exogenous demographic variables and all controls. The same pattern of results discussed below emerges across all three models, i.e. our results do not appear to be the result of the inclusion of these control variables. We thank an anonymous reviewer for bringing our attention to this issue.

${ }^{13}$ While the deficit is perhaps not as clearly an 'economic' issue are is the unemployment or inflation rates, it is nevertheless connected to economic performance (e.g. growing deficits in recession times due to a smaller tax base and 
post-election wave of the survey and the reference point was 1992, i.e. the beginning of President Clinton's administration. ${ }^{14}$ Respondents on the 2008-9 Panel, meanwhile, were asked this question in both May and July 2009 with a reference point of January 2009, i.e. the beginning of President Obama's term in office. In both cases the question admits an unambiguously correct response that is potentially inconvenient for one partisan team. In the former case, a budget deficit in 1992 had turned into a budget surplus by 2000, a fact that out-partisans (i.e. Republicans) should be less likely to report, knowing that it speaks favorably to the economic record of President Clinton. Meanwhile, the year 2009 saw a deficit in January grow larger month by month due to efforts to combat the financial crisis, a fact potentially inconvenient for inpartisans (i.e. Democrats). We thus expect lower levels of knowledge among out-partisans in 2000 and in-partisans in 2009. Hypothesis 1 posits a positive effect of disagreement on answering correctly for partisans in these two groups.

We predict deficit knowledge $(1=$ correct, $0=$ incorrect $)$ with a logit model that includes the interaction between network disagreement and partisanship and the controls discussed earlier. We present the full results in the online appendix and concentrate on Figure 1, which plots the average predicted probability of a correct response by partisanship and network disagreement. As a first point, we can note that partisanship is related to knowledge as we expected: in-partisans were more likely to answer correctly in 2000 and less likely to answer correctly in May and July 2009. This difference was sizeable in all years, with in-partisans being, on average, approximately 22 per cent more likely to be correct in 2000 but 14 per cent and 19 per cent less likely to be correct in May and July 2009 respectively. ${ }^{15}$ The correctness of a respondent's perceptions of the deficit is strongly related to their partisan loyalties.

We now turn to the role of network disagreement where we see partial evidence in favor of Hypothesis 1. Disagreement is estimated to have a positive, but statistically insignificant, influence on an out-partisan's likelihood of answering correctly in the year 2000. The results from the two 2008-9 ANES Panel surveys are likewise mixed. While knowledge does not vary alongside network disagreement for in-partisans in May 2009, a positive and statistically significant relationship between disagreement and knowledge does emerge for in-partisans two months later in July. Notably, the substantive effect of disagreement is sizeable in both 2000 among out-partisans and July 2009 among in-partisans, albeit more precisely measured in the latter instance. The estimated change in the probability of a correct response per one unit change in disagreement is approximately 3-4 per cent in both cases, which yields average predicted gains in knowledge of approximately 20 per cent when moving from the 5 th to 95 th percentile in disagreement. ${ }^{16}$ Figure 1 thus offers some qualified evidence in support of the role of network disagreement in constraining partisan motivated reasoning.

Recall that individuals participating in the July 2009 wave of the ANES 2008-9 panel may also have completed the May 2009 survey. ${ }^{17}$ This offers us the possibility of exploring how network

increased welfare spending). In addition, previous studies have connected knowledge of the deficit both to partisan motivated reasoning, e.g. Bartels (2008), and to discussions concerning the extent of economic-based retrospective voting (e.g. Brender and Drazen 2008; Healy and Malhotra 2013; Hellwig and Marinova 2015). Deficit knowledge is thus a good indirect indicator of economic knowledge, particularly given the omission of knowledge measures of these other indicators on these surveys.

${ }^{14}$ Half of the 2000 ANES sample received this question in the pre-election wave and half in the post-election wave. As network disagreement was measured on the post-election wave, we focus only on the latter sample.

${ }^{15}$ The average marginal effects of partisanship (i.e. the difference between in-partisans and out-partisans) from a model without the interaction with disagreement was 0.22 [95\% CI: $0.13,0.32],-0.14[-0.20,-0.08]$ and $-0.19[-0.25,-0.13]$ respectively. Partisanship remains significant in the interaction models where the coefficient indicates differences in knowledge among those with a disagreement score of 0 , which covers respondents that have an equal number of agreeing and disagreeing discussion partners.

${ }^{16}$ In 2000: $b_{\text {out-partisan }}=0.03[-0.02,0.08]$; in July 2009: $b_{\text {in-partisan }}=0.04[0.01,0.06]$.

${ }^{17} 2,389$ respondents completed the May wave, while 2,178 of these respondents also completed the July wave. 

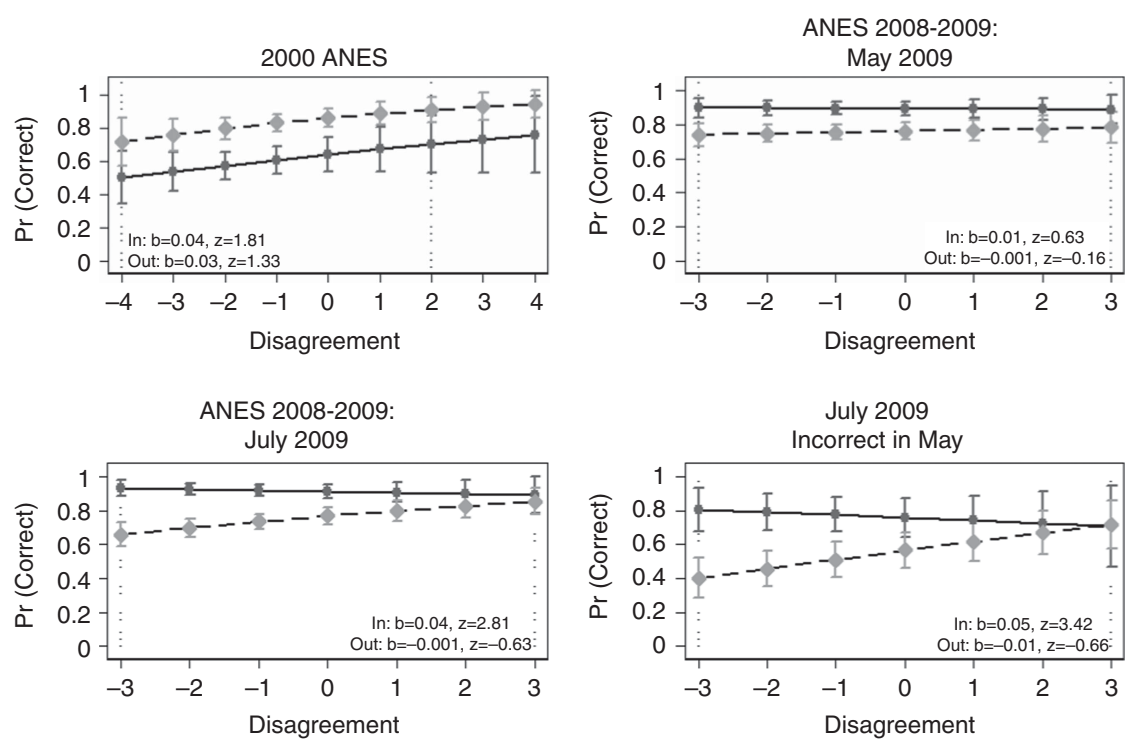

$\longrightarrow$ Out-Partisan

--- In-Partisan

Figure 1. Network disagreement and knowledge of the federal budget deficit.

Notes: Markers provide the average predicted probability of a correct answer ( $w / 95 \%$ confidence intervals) by partisanship and network disagreement (x-axis). Information regarding the slope of each line and its statistical significance is provided in each subgraph. Dotted lines represent the 5th and 95th percentile of network disagreement. See Table A6 for the full results. In-Partisans = Democrats, Out-Partisans $=$ Republicans in both waves.

disagreement affects learning via an exploration of July responses among respondents that were incorrect in May. We did this by adding a dummy variable for respondent correctness in May to the July 2009 model and then recalculating the average predicted probability of a correct response among previously incorrect respondents; the final subgraph of Figure 1 provides the results. Out-partisans incorrect in May have a high predicted probability of being correct in July regardless of the level of network disagreement. More intriguingly, we find a strong positive effect of network disagreement among previously incorrect in-partisans consistent with Hypothesis 1. This relationship, moreover, is substantial albeit quite noisy; previously incorrect in-partisans at the 5th percentile of disagreement have a predicted probability of a correct response in July of $0.40[0.28,0.52]$ while those at the 95th percentile are nearly twice as likely to be correct on average $(0.72[0.58,0.86])$. In this case disagreement appears to be facilitating the learning of partisan incongruent beliefs about the economy.

\section{Partisanship, disagreement and economic evaluations}

We provide a second, and perhaps harder, test of the argument that network disagreement will be associated with an attenuation of partisan motivated reasoning through an exploration of evaluations of the national economy. We say 'harder' because it is possible for partisans to accept facts about the world but nevertheless interpret them in such a way as to deny their negative partisan implications (Bisgaard 2015; Gaines et al. 2007). Given the important role retrospective evaluations play in vote choices, this relationship is crucial to investigate.

Respondents on all five surveys were asked to indicate whether the economy was better, about the same or worse relative to some reference point in the past, although there was some variation in the wording of the questions. Respondents to the 1992 CNEP survey were asked to evaluate the state of the economy relative to two years prior. Respondents on the 2000 ANES TS, on the other hand, were asked to indicate whether the economy was better/worse/about the same 
Table 1. Economic evaluations across the surveys

\begin{tabular}{|c|c|c|c|c|}
\hline & $\%$ Better & $\%$ Same & $\%$ Worse & $\mathrm{Chi}^{2}(2)=$ \\
\hline \multicolumn{5}{|l|}{1992 CNEP } \\
\hline All & 9.2 & 26.7 & 64.2 & \\
\hline In-Partisans & 15.7 & 36.2 & 48.1 & \\
\hline Out-Partisans & 3.9 & 17.9 & 78.3 & $123.9, p<0.01$ \\
\hline \multicolumn{5}{|l|}{2000 ANES TS } \\
\hline All & 72.7 & 22.2 & 5.2 & \\
\hline In-Partisans & 80.5 & 14.7 & 4.8 & \\
\hline Out-Partisans & 67.8 & 27.4 & 4.9 & $16.9, p<0.01$ \\
\hline \multicolumn{5}{|c|}{2002 ANES Panel } \\
\hline All & 39.1 & 43.0 & 16.9 & \\
\hline In-Partisans & 27.6 & 50.7 & 21.7 & \\
\hline Out-Partisans & 50.5 & 39.3 & 10.2 & $95.0, p<0.01$ \\
\hline \multicolumn{5}{|c|}{2006 ANES Pilot } \\
\hline All & 31.7 & 38.2 & 30.1 & \\
\hline In-Partisans & 48.3 & 37.1 & 14.6 & \\
\hline Out-Partisans & 17.9 & 40.3 & 41.9 & $84.0, p<0.01$ \\
\hline \multicolumn{5}{|c|}{ ANES: May 2009} \\
\hline All & 15.2 & 31.8 & 53.0 & \\
\hline In-Partisans & 20.9 & 36.2 & 42.9 & \\
\hline Out-Partisans & 10.4 & 26.9 & 62.7 & $83.5, p<0.01$ \\
\hline \multicolumn{5}{|c|}{ ANES: July 2009} \\
\hline All & 12.4 & 31.1 & 56.5 & \\
\hline In-Partisans & 18.8 & 39.8 & 41.4 & \\
\hline Out-Partisans & 6.0 & 20.4 & 73.6 & $211.7, p<0.01$ \\
\hline
\end{tabular}

Note: Cells provide the percentage of respondents giving each response. The final column provides the results of a chi-squared test between in- and out-partisans. Republicans = in-partisans in 1992, 2002 and 2006 (out-partisans the other years). Democrats =in-partisans in 2000 and May/July 2009 (out-partisans the other years).

'compared to 1992 ' ${ }^{18}$ Respondents to the 2002 Panel and 2006 Pilot surveys, meanwhile, were both asked to evaluate the state of the economy relative to a year prior. Finally, respondents to the 2008-9 ANES Panel were asked in May 2009 and July 2009 to evaluate the state of the economy relative to January 2009, i.e. when President Obama officially became President. ${ }^{19}$ In the analyses that follow we code these measures so that higher scores indicate a belief that the economy was doing better than in the reference period. For some of these measures respondents could only answer on a three-point scale (1992 CNEP, 2006 ANES Pilot), while the remainder enabled respondents to also indicate whether the economy was much or somewhat better/worse. All in-text analyses will use focus on a three-point Worse/Same/Better structure. Table 1 provides descriptive statistics for each measure.

Much as with our earlier analyses we are principally concerned with the evaluations of inpartisans in negative economic conditions and the reactions of out-partisans during good times as these contexts are the ones wherein partisan defensive motivations are perhaps most easily observed. We predicted each retrospective evaluation measure using an ordinal logit model using partisanship, network disagreement, their interaction and the same bevy of control variables as

\footnotetext{
${ }^{18}$ These respondents were also asked about the state of the national economy relative to a year prior. Unfortunately, this measure was contained in the pre-election wave of the survey, while the network measures used here appeared in the postelection wave.

${ }^{19}$ Respondents to this survey were also asked for their retrospective economic assessments in October and November 2008 in waves that come after the measurement of social disagreement. However, the financial crisis of 2008 led to near unanimity in perceptions of the economy, with over $90 \%$ of Republicans and Democrats indicating that the economy was worse than a year prior. As this extreme reality constraint nearly extinguished partisan biases we will not investigate it in the text. Our analyses of these items are provided in online appendix Table A5; here we show that in-partisans continue to provide more optimistic accounts of the economy (mainly by saying the economy is the 'same' as the year prior, as virtually nobody says 'better'). Both in- and out-partisans become slightly more likely to say that the economy is 'worse' than a year prior with increasing exposure to disagreement, but the effect is insubstantial due to the extremely high base rate.
} 

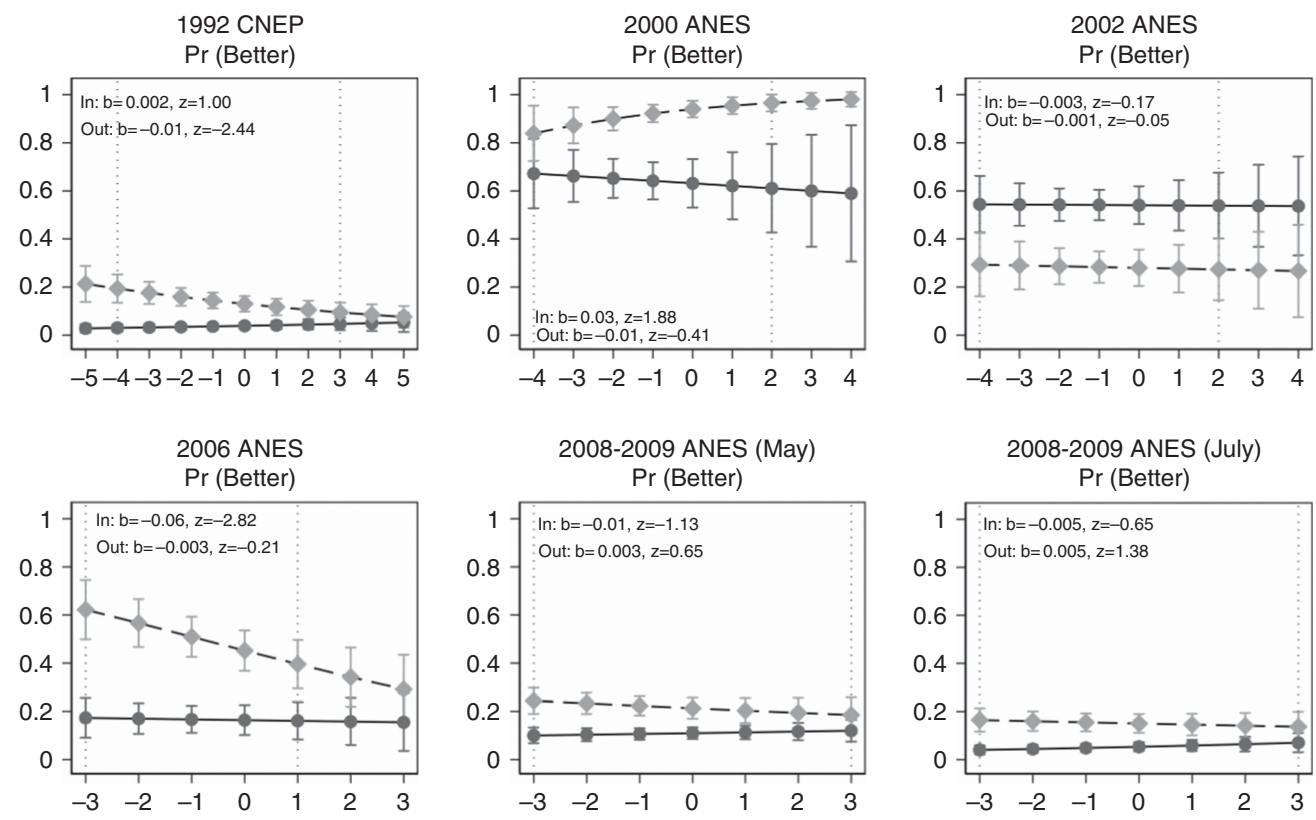

- Out-Partisan

--- In-Partisan

Figure 2. Network disagreement and partisan differences in economic evaluations.

Notes: Markers provide the average predicted probability of the respondent saying the economy is 'better' ( $w / 95 \%$ confidence intervals) by partisanship and network disagreement ( $\mathrm{x}$-axis). Information regarding the slope of each line and its statistical significance is provided in each subgraph. Dotted lines represent the 5th and 95th percentile of network disagreement. Republicans $=$ in-partisans in 1992, 2002, and 2006 (out-partisans the other years). Democrats = in-partisans in 2000 and May/July 2009 (out-partisans the other years).

predictors. To facilitate interpretation of these results we focus on Figure 2, which plots the average predicted probability of a respondent saying that the economy is 'better' by the level of disagreement in their network (x-axis) and their partisanship. Evidence consistent with Hypothesis 1 would thus take the form of a positively sloped line for out-partisans in the good economic conditions of 2000 and 2006 (e.g. Republicans and Democrats respectively) and negatively sloped lines for in-partisans in 1992, 2002 and in May and July 2009 (i.e. Republicans in 1992 and 2002 and Democrats in 2009).

As Table 1 shows, in-partisans adopted more positive evaluations of the national economy than out-partisans in all years save for 2002. These differences remain statistically significant in multivariate models. However, Figure 2 provides meager evidence that disagreement affected these differences in the manner hypothesized to occur. We can begin here with an analysis of disagreement during positive economic conditions, i.e. in the years 2000 and 2006 where unemployment was low, consumer confidence high and economic growth positive. The critical test, recall, is whether disagreement is associated with increased positivity in the evaluations of out-partisans as revealed by a positively sloped line in Figure 2, i.e. with whether Republicans (Democrats) are more likely to give President Clinton (Bush) his due for good economic performance. The evidence is not positive on this front; in 2000, out-partisans actually become a bit less likely to say that the economy is 'better' as disagreement increases while in 2006 a flat line emerges for out-partisans across network disagreement. Indeed, the sub-graph for 2006 shows in-partisans become significantly more negative about the economy as disagreement increases, indicating that disagreement for these individuals may be facilitating inaccurate evaluations. ${ }^{20}$

\footnotetext{
${ }^{20}$ Among in-partisans, the average marginal effect of disagreement on the probability of saying 'better' is $\mathrm{b}=$ $-0.06[-0.10,-0.02]$, while for out-partisans it was $-0.003[-0.03,0.02]$.
} 
There is thus little evidence that network disagreement facilitates more accurate evaluations among out-partisans in good economic conditions.

The remainder of the surveys occurred in more negative economic contexts. In such conditions out-partisans should readily say that the economy is poor, while in-partisans may be more likely to say it is good to defend their partisan team. ${ }^{21}$ Thus, the key question is whether disagreement breaks down this latter pattern (i.e. leads to more pessimistic evaluations of the economy among in-partisans) as revealed by a negatively sloped line in the figure. Figure 2 provides little evidence in favor of this conclusion outside of the 1992 CNEP survey. In-partisans on this survey do report increasingly pessimistic readings of the national economy as their exposure to interpersonal disagreement increases. For instance, an in-partisan at the 5th percentile of network disagreement, i.e. low levels of disagreement, has an average predicted probability of $0.19[0.13,0.25]$ for saying 'better' and $0.37[0.29,0.46]$ of saying 'worse'. Meanwhile, in-partisans at the 95th percentile, i.e. high disagreement, do appear much more pessimistic, being both less likely to say 'better' $(0.09[0.05,0.14])$ and more likely to say worse $(0.57[0.47,0.68])$. However, in none of the other three surveys does disagreement have a significant negative (positive) effect on the probability that in-partisans say the economy is better (worse). ${ }^{22}$ To the extent that partisan groups look similar in these surveys it appears to be the result of the broader economy exerting a reality constraint on respondents. Figure 2 thus provides weak evidence that network disagreement attenuates partisan motivated reasoning when it comes to economic evaluations.

\section{Network disagreement and partisan identity, an interlude}

There is inconsistent evidence in favor of the proposition that social disagreement undermines partisan motivated reasoning. Why is this so? One possibility is that our supposition that disagreement weakens partisan identities, and hence the motivation to defend them, may be incorrect. After all, both partisan identities and political discussion networks may be characterized as relatively stable due to the former's early development and the latter being principally composed of close, and stable, relationships (Campbell et al. 1960; Klofstad, McClurg, and Rolfe 2009). ${ }^{23}$ Perhaps this link in the causal chain is missing and that is why we fail to see stronger effects. We test this possibility in analyses reported in online Appendix A. Of particular interest are analyses from the 2008-9 ANES Panel wherein we have both temporal distance between disagreement and measures of partisan identity extremity as well as multiple indicators of extremity recorded anywhere from one to ten months later in time. This contrasts with the limited existing work on this subject that tends only to examine a single recording of extremity. ${ }^{24}$ Notably, partisans in highly disagreeing networks in September 2008 report substantially less extreme identities in future survey waves even while controlling for pre-September reports of identity extremity. This pattern also emerges in analyses of the cross-sectional datasets. While partisans in disagreeing networks possess weaker partisan identities and thus putatively possess weaker motivations to defend those identities, they nevertheless do not evince a reduced

\footnotetext{
${ }^{21}$ In-partisans in 1992 and 2002 would be Republican respondents, while in-partisans for the two 2009 waves would be Democrats.

${ }^{22}$ To be clear, the average estimated effect of disagreement on the probability of the respondent saying 'better' is negative, but it is small and noisy: $-0.003[-0.04,0.03]$ in 2002, $-0.01[-0.03,0.01]$ in May 2009, and $-0.004[-0.02,0.01]$ in July 2009.

${ }^{23} \mathrm{We}$ thank an anonymous reviewer for making this point salient.

${ }^{24}$ Klofstad, Sokhey, and McClurg (2013), for instance, only examine a single report of identity strength whereas we focus on four such reports. In addition, we also include analyses of partisan identity ambivalence, which contributes to prior work that has focused primarily on extremity (either directly so or via measures of identity change, e.g. Sinclair 2012). We find that disagreement is associated with increased ambivalence which is consistent with cross-sectional evidence (e.g. Lavine, Johnston, and Steenbergen 2012) as well as with studies of disagreement and ambivalence in issue attitudes or candidate preferences (e.g. Visser and Mirabile 2004).
} 
likelihood of consistently adopting identity-incongruent economic evaluations. We discuss some reasons why in our concluding discussion.

\section{Conclusion}

We have investigated whether interpersonal disagreement mitigates partisan differences in economic perceptions by undermining the individual's underlying motivation to defend their partisan team against negative information. Using the best available observational data we have shown limited evidence in favor of this possibility. On the one hand, we found some evidence that exposure to disagreement may facilitate the learning of inconvenient political facts, but some of this evidence was statistically imprecise (i.e. the 2000 ANES analyses) and the effect failed to manifest in another survey (May 2009 analyses). On the other hand, we found scant evidence that the level of disagreement in a partisan's network was associated with an attenuation of partisan biases in evaluations of the national economy outside of the 1992 CNEP survey. At the very least, we feel that our analyses suggest that network disagreement is no easy panacea for concerns over partisan motivated reasoning. In the remainder of this article we will discuss some of the implications of our study for future research.

We begin by discussing the potential role of self-selection in this study. As noted earlier, we utilize observational data, which raises the specter that partisans will select into disagreeing or agreeing networks based on background characteristics. It is thus worth considering the potential role these selection pressures may have on the results found in this study. When it comes to our analyses of economic evaluations and factual knowledge, the concern with selfselection is that individuals prone to avoiding directional motivated reasoning will self-select into disagreeable contexts and thus evidence of a reduction in partisan motivated reasoning is spurious. Much as above we cannot fully evade such concerns with observational evidence. However, by controlling for need for cognition and need to evaluate we believe we are capturing some of this process. Moreover, we actually found scant evidence that partisans within disagreeable networks showed lesser evidence of partisan motivated reasoning. Given that selection processes, to the extent that they are present, are likely pushing in the opposite direction, we feel that this further speaks to the validity of our results. However, future work could build on these findings, and those related to partisan identity strength, by leveraging natural experiments that introduce exogenous variation into networks, as in Klofstad's (2010) study of dorm assignments. In the end, we believe that our results offer the most comprehensive available portrait of the relationship between social disagreement and partisan motivated reasoning, self-selection warts and all.

Perhaps the most important question to emerge from this study concerns how we should interpret the rather mixed evidence that emerges in our analyses. We see at least two possibilities here. First, the mixed evidence here may suggest that network disagreement plays little consistent role in undermining partisan defensive motivations, at least in this domain. While interpersonal disagreement may undermine a partisan's identity strength, and hence their motivation to counter-argue inconsistent information, it may nevertheless be the case that these partisans still have sufficient motivation and resources to rebut party-incongruent information. Moreover, the very act of discussion may prompt individuals to more deeply consider information and, via this enhanced elaboration, formulate issue-specific attitudes more resistant to change even in the midst of weakened partisan identities (Levendusky, Druckman, and McLain 2016). If this is the case, then scholars interested in understanding the nature of partisan motivated reasoning, and particularly its limits, may be better off exploring broader contextual features of the environment such as elite polarization, the nature of a nation's political institutions and their resulting influence on partisan identities, or the nature of news discourse, than focusing on interpersonal relationships (e.g. Druckman, Peterson, and Slothuus 2013; Lupu 2015; Robison and Mullinix 2016). 
An alternative interpretation of the results reported here is that the influence of disagreement may in fact be conditional in nature. For instance, it may be no accident that we observed stronger results on measures of factual knowledge than on retrospective evaluations as partisans may come to accept identity-incongruent facts but simply respond by rationalizing them on measures that invite more subjectivity (Bisgaard 2015; Gaines et al. 2007). Disagreement may thus attenuate partisan motivated reasoning, but do so only in specific domains. Alternatively, perhaps the network batteries explored here do not capture the types of social interactions that matter. The name generator batteries used on the surveys tend to capture close ties, although a fair proportion of reported discussants nevertheless stem from 'weak' tie relations (Klofstad, McClurg, and Rolfe 2009). Notably, Mutz and Mondak (2006) show that discussions with weak ties found in the workplace were more effective in fostering political tolerance than was discussion with relatives, i.e. stronger ties. This fits with Klar's (2014) study which focused on discussion between individuals that did not know each other and thus had little expectation of future interactions. Perhaps, then, we should look to discussions fostered outside of one's peer networks, for instance on the internet, as a source of attenuation for partisan biases (Wojcieszak and Mutz 2009). However, on this last point we can note that incorporating indicators of discussion frequency and tie strength into our measure of network disagreement did not change our conclusions (see online Appendix D). Regardless, one area for future work would be to theorize about potential conditionality for the influence of network disagreement and test it with appropriate data; to the extent that these conditional factors fail, then the first interpretation would gain influence over the latter. Whichever explanation ultimately finds support will have deep political, normative and empirical implications for how we understand the nature and quality of public opinion.

Supplementary material. Data replication sets can be found in Harvard Dataverse at: https://dx.doi.org/doi:10.7910/DVN/ CHBAYB and online appendices at: doi: 10.1017/S0007123418000315

Acknowledgements. I am thankful to Martin Bisgaard, Matt Levendusky and participants at the Comparative Politics workshop at the Department of Political Science, Aarhus University, for their helpful comments on a prior version of this manuscript.

The data, replication instructions, and the data's codebook can be found at https://dataverse.harvard.edu/dataset.xhtml? persistentId=doi: $10.7910 /$ DVN/CHBAYB.

\section{References}

Ahler D and Sood G (2018) The parties in our heads: misperceptions about party composition and their consequences. Journal of Politics 80 (3): 981.

Barabas J (2004) How deliberation affects policy opinions. American Political Science Review 98 (4): 687-701.

Bartels LM (2008) Unequal Democracy: The Political Economy of the New Gilded Age. Princeton, NJ: Princeton University Press.

Bisgaard M (2015) Bias will find a way: economic perceptions, attributions of blame, and partisan-motivated reasoning during crisis. Journal of Politics 77 (3): 849-60.

Bloom PBN and Levitan LC (2011) We're closer than I thought: social network heterogeneity, morality, and political persuasion. Political Psychology 32 (4): 643-65.

Bolsen T, Druckman JN and Cook FL (2014) The influence of partisan motivated reasoning on public opinion. Political Behavior 36 (2): 235-62.

Brender A and Drazen A (2008) How do budget deficits and economic growth affect reelection prospects? Evidence from a large panel of countries. The American Economic Review 98 (5): 2203-20.

Bullock J, Gerber AS, Hill SJ and Huber SA (2015) Partisan bias in factual beliefs about politics. Quarterly Journal of Political Science 10, 519-78.

Buttice M, Huckfeldt R and Ryan JB (2009) Polarization, attribution, and communication networks in the 2006 congressional elections. In Mondak J and Mitchell DG, (eds) Fault Lines: Why the Republicans Lost Congress. New York: Routledge, pp. 42-60.

Campbell A, Converse PE, Miller WE and Stokes DE (1960) The American Voter. Chicago, IL: The University of Chicago Press. 
Chaiken S, Giner-Sorolla R and Chen S (1996) Beyond accuracy: defense and impression motives in heuristic and systematic processing. In Gollwitzer PM and Bargh JA, (eds) The Psychology of Action: Linking Motivation and Cognition in Behavior. New York: Guilford Press, pp. 553-78.

Conover PJ, Feldman S and Knight K (1986) Judging inflation and unemployment: the origins of retrospective evaluations. Journal of Politics 48, 565-88.

Druckman JN (2014) Pathologies of studying public opinion, political communication, and democratic responsiveness. Political Communication 31 (3): 467-92.

Druckman JN, Fein J and Leeper TJ (2012) A source of bias in public opinion stability. American Political Science Review 106 (2): 430-54.

Druckman JN, Levendusky MS and McLain A (2018) No need to watch: how the effects of partisan media can spread via inter-personal discussions. American Journal of Political Science 62 (1): 99-112.

Druckman JN, Peterson E and Slothuus R (2013) How elite partisan polarization affects public opinion formation. American Political Science Review 107 (1): 57-79.

Duch RM and Stevenson R (2008) The Economic Vote: How Political and Economic Institutions Condition Electoral Results. Cambridge: Cambridge University Press.

Duch RM, Palmer HD and Anderson CJ (2000) Heterogeneity in perceptions of national economic conditions. American Journal of Political Science 44 (4): 635-52.

Enns PK and McAvoy GE (2012) The role of partisanship in aggregate opinion. Political Behavior 34 (4): 627-51.

Enns PK, Kellstedt PM and McAvoy GE (2012) The consequences of partisanship in economic perceptions. Public Opinion Quarterly 76 (2): 287-310.

Evans G and Andersen R (2006) The political conditioning of economic perceptions. Journal of Politics 68 (1): $194-207$.

Evans G and Pickup M (2010) Reversing the causal arrow: the political conditioning of economic perceptions in the 2000-2004 presidential election cycle. Journal of Politics 72 (4): 1236-51.

Fiorina MP (1981) Retrospective Voting in American National Elections. New Haven, CT: Yale University Press.

Gaines BJ, Kuklinski JH, Quick PJ, Peyton B and Verkuilen J (2007) Same facts, different interpretations: partisan motivation and opinion on Iraq. Journal of Politics 69 (4): 957-74.

Gerber A and Green D (1999) Misperceptions about perceptual bias. Annual Review of Political Science 2, 189-210.

Haller HB and Norporth H (1997) Reality bites: news exposure and economic opinion. Public Opinion Quarterly 61, 555-75.

Healy A and Malhotra N (2013) Retrospective voting reconsidered. Annual Review of Political Science 16, $285-306$.

Hellwig T and Marinova DM (2015) More misinformed than myopic: economic retrospections and the voter's time horizon. Political Behavior 37, 865-87.

Hetherington MJ (1996) The media's role in forming voters' national economic evaluations in 1992. American Journal of Political Science 40 (2): 372-95.

Huckfeldt R (2001) The social communication of political expertise. American Journal of Political Science 45 (2): $425-38$.

Huckfeldt R, Mendez JM and Osborn T (2004) Disagreement, ambivalence, and engagement: the political consequences of heterogenous networks. Political Psychology 25 (1): 65-95.

Huckfeldt R and Sprague J (1995) Citizens, Politics, and Social Communication. Cambridge: Cambridge University Press.

Huddy L, Mason L and Aarøe L (2015) Expressive partisanship: campaign involvement, political emotion, and partisan identity. American Political Science Review 109 (1): 1-17.

Isenberg DJ (1986) Group polarization: a critical review and meta-analysis. Journal of Personality and Social Psychology 50 (6): 1141-51.

Iyengar S and Hahn KS (2009) Red media, blue media: evidence of ideological selectivity in media use. Journal of Communication 59 (1): 19-39.

Jerit J and Barabas J (2012) Partisan perceptual bias and the information environment. Journal of Politics 74 (3): $672-84$.

Klar S (2014) Partisanship in a social context. American Journal of Political Science 58 (3): 687-704.

Klofstad CA (2010) The lasting effect of civic talk on civic participation: evidence from a panel study. Social Forces 88 (5): 2353-75.

Klofstad CA, McClurg SD and Rolfe M (2009) Measurement of political discussion networks: a comparison of two 'Name Generator' procedures. Public Opinion Quarterly 73 (3): 462-83.

Klofstad CA, Sokhey AE and McClurg SD (2013) Disagreeing about disagreement: how conflict in social networks affects political behavior. American Journal of Political Science 57 (1): 120-34.

Kunda Z (1990) The case for motivated reasoning. Psychological Bulletin 108 (3): 480-98.

Larcinese V, Puglisi R and Snyder Jr JM (2011) Partisan bias in economic news: evidence of the agenda-setting behavior of U.S. newspapers. Journal of Public Economics 95, 1178-89.

Lavine HG, Johnston CD and Steenbergen MR (2012) The Ambivalent Partisan: How Critical Loyalty Promotes Democracy. Oxford: Oxford University Press.

Lebo MJ and Cassino D (2007) The aggregated consequences of motivated reasoning and the dynamics of partisan presidential approval. Political Psychology 28 (6): 719-46. 
Leeper TJ and Slothuus R (2014) Political parties, motivated reasoning, and public opinion formation. Advances in Political Psychology 35 (1): 129-56.

Levendusky MS, Druckman JN and McLain A (2016) How group discussions create strong attitudes and strong partisans. Research and Politics 1-6.

Lodge $\mathbf{M}$ and Taber CS (2006) Motivated skepticism in the evaluation of political beliefs. American Journal of Political Science 50 (3): 755-69.

Lord CG, Ross L and Lepper MR (1979) Biased assimilation and attitude polarization: the effects of prior theories on subsequently considered evidence. Journal of Personality and Social Psychology 27 (11): 2098-2109.

Lupia A (2002) Who can persuade whom? Implications from the nexus of psychology and rational choice theory. In Kuklinski JH, (ed.) Thinking about Political Psychology. Cambridge: Cambridge University Press, pp. 51-88.

Lupton RN, Singh SP and Thornton JR (2015) The moderating impact of social networks on the relationships among core values, partisanship, and candidate evaluations. Political Psychology 36 (4): 399-414.

Lupton RN and Thornton J (2017) Disagreement, diversity, and participation: examining the properties of several measures of political discussion networks. Political Behavior 39 (3): 585-608.

Lupu N (2015) Party polarization and mass partisanship: a comparative perspective. Political Behavior 37, 331-56.

Lyons J and Sokhey AE (2017) Discussion networks, issues, and perceptions of polarization in the American electorate. Political Behavior 39 (4): 967-88.

Mendelberg T (2002) The deliberative citizen: theory and evidence. In Carpini MXD and Shapiro RY, (eds) Research in Micropolitics: Political Decision Making, Deliberation, and Participation. Bingley: Emerald Group Publishing, pp. 151-93.

Mullinix KJ (2016) Partisanship and preference formation: competing motivations, elite polarization, and issue importance. Political Behavior 38 (2): 383-411.

Mutz DC (2006) Hearing the Other Side: Deliberative versus Participatory Democracy. Cambridge: Cambridge University Press.

Mutz DC (2002a) Cross-cutting social networks: testing democratic theory in practice. American Political Science Review 96 (1): 111-26.

Mutz D (2002b) The consequences of cross-cutting networks for political participation. American Journal of Political Science 46 (4): 838-55.

Mutz DC and Mondak JJ (2006) The workplace as a context for cross-cutting political discourse. Journal of Politics 68 (1): 140-55.

Nir L (2005) Ambivalent social networks and their consequences for participation. International Journal of Public Opinion Research 17 (4): 422-42.

Nir L (2011a) Disagreement and opposition in social networks: does disagreement discourage turnout? Political Studies 59 (3): 674-92.

Nir L (2011b) Motivated reasoning and public opinion perception. Public Opinion Quarterly 75 (3): 504-32.

Pattie C and Johnston R (2008) It's good to talk: talk, disagreement, and tolerance. British Journal of Political Science 38, 677-98.

Price V, Cappella JN and Nir L (2002) Does disagreement contribute to more deliberative opinion? Political Communication 19, 95-112.

Prior M, Sood G and Khanna K (2015) You cannot be serious: the impact of accuracy incentives on partisan bias in reports of economic perceptions. Quarterly Journal of Political Science 10, 489-518.

Ramirez MD and Erickson N (2014) Partisan bias and information discounting in economic judgments. Political Psychology 35 (3): 401-15.

Redlawsk DP, Civettini AJW and Emmerson KM (2010) The affective tipping point: do motivated reasoners ever 'get it'? Political Psychology 31 (4): 563-93.

Robison Joshua (2018) "Replication Data for: Does Social Disagreement Attenuate Partisan Motivated Reasoning? A Test Case Concerning Economic Evaluations”, https://doi.org/10.7910/DVN/CHBAYB, Harvard Dataverse, V1.

Robison J, Leeper TJ and Druckman JN (2018) Do Disagreeable political discussion networks undermine attitude strength? Political Psychology 39 (2): 479-94.

Robison J and Mullinix K (2016) Elite polarization and public opinion: how polarization is communicated and its effects. Political Communication 33 (2): 261-82.

Sinclair B (2012) The Social Citizen: Peer Networks in Political Behavior. Chicago, IL: The University of Chicago Press.

Sokhey AE and McClurg SD (2012) Social networks and correct voting. Journal of Politics 74 (3): 751-64.

Soroka SN (2006) Good news and bad news: asymmetric responses to economic information. Journal of Politics 68 (2): 372-85.

Stanig P (2013) Political polarization in retrospective economic evaluations during recessions and recoveries. Electoral Studies 32, 729-45.

Stroud NJ (2011) Niche News: The Politics of News Choice. Oxford: Oxford University Press.

Tilley J and Hobolt SB (2011) Is the government to blame? An experimental test of how partisanship shapes perceptions of performance and responsibility. Journal of Politics 73 (2): 316-30. 
Visser PS and Mirabile RR (2004) Attitudes in the social context: the impact of social network composition on individuallevel attitude strength. Journal of Personality and Social Psychology 87 (6): 779-95.

Wojcieszak ME (2012) On strong attitudes and group deliberation: relationships, structure, changes, and effects. Political Psychology 33 (2): 225-42.

Wojcieszak ME and Mutz DC (2009) Online groups and political discourse: do online discussion spaces facilitate exposure to political disagreement? Journal of Communication 59, 40-56. 